\title{
Phytoclimatic Dynamics of Mediterranean Forests under Climate Change. A Case Study in a Southern European Pinus sylvestris L. Stand
}

\author{
Javier M. García-López, Carmen Allué
}

Regional Government of Castilla y León, Environmental Service, Burgos, Spain.

Email: garlopjv@jcyl.es

Received January $5^{\text {th }}, 2013$; revised February $4^{\text {th }}, 2013$; accepted February $24^{\text {th }}, 2013$

\begin{abstract}
Some effects of climate change on the composition and competitive capacity of southern European Pinus sylvestris L. forests in the Mediterranean basin were evaluated. The variation over the period 1910-2008 through 30-year mobile averages of a Phytoclimatic Suitability Index (PSI) of the main tree species of the forest cover are used to indicate the competitive hierarchy of Pinus sylvestris and Fagus sylvatica L. The methodology was applied at a specific location on the Spanish south-facing slopes of the Pyrenees mountain range in the Iberian Peninsula, where the increase in the average temperature was $1.4^{\circ} \mathrm{C}$ in the period of observation. The results indicated that the apparent equilibrium between the two species studied changed from the 1934-1963 average. Due to the loss of competitive capacity of Scots pine with respect to European beech, particularly from the years 1970-1999, the model predicted an inversion of the situation as it was up until now, so that beech had a higher PSI than pine. The phytoclimatic approach proposed here offers new methodological horizons for the study of the effects of climate change on the future of the forests.
\end{abstract}

Keywords: Biodiversity; Complexity; Suitability; Competition; Phytoclimatology; Scots Pine; European Beech

\section{Introduction}

Forests are particularly sensitive to climate change, because the long life-span of trees does not allow for rapid adaptation to environmental changes [1-3]. Thus, forest conservation, management and planning is becoming more challenging in the perspective of climate change, needing adequate links between monitoring of environmental indicators and management practices $[4,5]$. Forest ecosystems can respond to climate change by shifting distribution, by remaining in isolated pockets of suitable environment (refugia), becoming extinct or by adapting its composition or structure to changing conditions $[6,7]$.

Particularly, the effects of climate change on the diversity of forest covers and on internal competitive relationships among the principal species constituting those covers seems likely to be one of the priority lines of research in the future [8,9]. Effective conservation strategies that offset the climate change threats to species persistence will be critical in maintaining species and genetic diversity $[10,11]$.

Several studies on the effects of climate change on forest composition in the last few years have tended to focus on the variation in distributions of the main forest tree species in relation to previously defined climatic envelopes, e.g. $[12,13]$. Particularly, recent studies have dealt with several aspects of the influence of climate change on European forests as a whole, e.g. [3,12,14-17].

Species that lie at the limits of their natural range of distribution appear to be particularly sensitive to the effects of climate change $[18,19]$. One such case is Scots pine (Pinus sylvestris L.), the pine with the largest natural area and the most widespread in Europe and Asia. This species occurs more or less from east to west, from eastern Siberia to Galicia, and north to south, from Scandinavia to the south of the Iberian Peninsula (Sierra Nevada) where the most southerly specimens are found.

Scots pine is a naturally-occurring species in taiga forests in northern Europe and Asia, being its northern area of distribution more or less continuous on plains, whereas in the south, in the Mediterranean basin, it is becoming increasingly fragmented and confined to mountain areas [20]. Because of the considerable economic and ecological wealth of this species in Spain [21] the vulnerability of natural and artificial stands to climate change is a matter of particular interest and concern, especially considering that the mountain ecosystems of southern Europe may be among the worst affected by such change $[22,23]$. 
This paper reports the assay of a phytoclimatic indicator that serves to assess the possible influence of climate change on the physiognomic dynamics of arboreal covers of $P$. sylvestris L. in southern Europe. Several authors, e.g. [12], have reported the enrichment of European alpine forests with deciduous broadleaf species, particularly with European beech (Fagus sylvatica L.) in P. sylvestris stands in the Spanish Pyrenees [24]. No satisfactory account seems to have been offered so far of what part of these changes in forest composition are likely to be related to forest management practices [21] and what part may be due to climate dynamics [3].

Recently there has been an upsurge of interest in studying climate change in community rather than individual terms [25] and in terms of biotic interactions [26]. The methodology presented in this paper seeks to advance further in this area of research. The comparative variation over time of phytoclimatic suitability indices of $P$. sylvestris and other tree species present in forest formations serves as an indicator of the ability of these species to compete. This variation is also an indicator of the foreseeable composition and structure of the forest mass and the vulnerability of Scots pine to climate change, and is used in defining alternatives for future management of these pine stands.

\section{Material and Methods}

We used the phytoclimatic niche-based model CLIMPAIR [27], which simultaneously assesses non-linear, non statistical and dual measurements of proximity/potentiality of a target site with respect to climatic ranges of plant/vegetation units (i.e. species or woodland types).

The traditional environmental space is founded in classic ecological niche theory [28] and is defined by climatic variables regarding temperature and precipitation. Through a specific transfer function [29], this space is replaced by a suitability space. This set of phytoclimatic distances evaluates the climatic suitability of a site for a species.

The model considers a 12-dimensional climatic hyperspace corresponding to the $n=12$ climatic variables (Table 1). Records of the occurrence of $P$. sylvestris and $F$. sylvatica forests are represented by a swarm of points in 12-dimentional climatic hyperspace. In this way, within the geographical scope of the model the respective species ranges or realised niches [30] can be explicitly defined by calculating convex hulls. Although many shapes could be used to enclose the points, the convex hull is defined as the smallest convex set enclosing them [31] and therefore reduces the amount of empty space compared with other volumes like parallelepipeds [32]. Each range thus takes the form of a convex hyperpolyhedron which can be explicitly defined by a set of vertices and linking edges.

In view of the complexity of explicitly determining the hyperpolyhedron for $n>2$, it is best calculated by means of projections onto $m$ climatic planes with no $V_{i} V_{j}$ repetition formed by climatic variables $V_{i}$ and $V_{j}$, where

$$
m=\left(\begin{array}{l}
n \\
2
\end{array}\right)=\frac{n(n-1)}{2}
$$

Each variable appears in $n-1 V_{i} V_{j}$ projections $(1 \leq i \leq n-1$ and $2 \leq j \leq n)$. The number of possible

Table 1. Phytoclimatic variables used.

\begin{tabular}{|c|c|c|}
\hline & Variable & Unit \\
\hline $\mathrm{K}$ & $\begin{array}{l}\text { Intensity of aridity. Calculated on the basis of the quotient } \mathrm{As} / \mathrm{Ah} \text {, where } \mathrm{Ah} \text { is the humid area of the climodiagram } \\
\text { ( } \mathrm{Pi} \text { curve above the } \mathrm{Ti} \text { curve, i.e., } 2 \mathrm{Ti}<\mathrm{Pi} \text { ) and } \mathrm{As} \text { is the dry area of the climodiagram (Pi curve below the Ti curve, } \\
\text { i.e., } 2 \mathrm{Ti}>\mathrm{Pi} \text { ). Ti and } \mathrm{Pi} \text { are the mean temperature and precipitation of the month } \mathrm{i}\end{array}$ & \\
\hline A & $\begin{array}{l}\text { Duration of aridity in the sense of GAUSSEN, that is the number of months in which the Ti curve is above the Pi curve, } \\
\text { i.e., } 2 \mathrm{Ti}>\mathrm{Pi}\end{array}$ & months \\
\hline $\mathrm{P}$ & Total annual precipitation & $\mathrm{Mm}$ \\
\hline $\mathrm{PE}$ & Minimum summer precipitation (June, July, August or September) & $\mathrm{Mm}$ \\
\hline TMF & Lowest monthly mean temperature & ${ }^{\circ} \mathrm{C}$ \\
\hline $\mathrm{T}$ & Mean annual temperature & ${ }^{\circ} \mathrm{C}$ \\
\hline $\mathrm{TMC}$ & Highest monthly mean temperature & ${ }^{\circ} \mathrm{C}$ \\
\hline TMMF & Average of the minima of the month with the lowest mean temperature & ${ }^{\circ} \mathrm{C}$ \\
\hline TMMC & Average of the maxima of the month with the highest mean temperature & ${ }^{\circ} \mathrm{C}$ \\
\hline HS & Certainty of frost. Calculated as the number of months in which $\mathrm{Ti}<=4^{\circ} \mathrm{C}$ & months \\
\hline PV & Period of free plant activity, calculated as the number of months in which $\mathrm{Ti}>=7.5^{\circ} \mathrm{C}$, not counting periods where $\mathrm{A}>0$ & months \\
\hline OSC & Thermal oscillation. Calculated as TMC-TMF & ${ }^{\circ} \mathrm{C}$ \\
\hline
\end{tabular}


combinations is less than a factorial to avoid redundancies, as projections $V_{i} V_{j}$ and $V_{j} V_{i}$ give the same information. For the $n=12$ climatic variables used $m=66$ polyhedrons are made for the two tree species (Equation (1)).

A target point $P$ whose coordinates are $\left(V_{i P} ; V_{j P}\right)$ in the plane $V_{i} V_{j}$ is suitable for a specific woodland type if it occurs inside the polyhedron that represents the projection of the plane of the full range of the type, i.e. the entire hyperpolyhedron in the climatic 12-dimensional hyperspace. The target point's position with respect to the projected polyhedron is related to its degree of compatibility or suitability by a transfer function.

The phytoclimatic position function $\varphi_{P}^{V_{i}}$ used is a parabolic function (Equation (2)).

$$
\varphi_{P}^{V i}=K_{V i_{p}}\left[\frac{2 V i_{p}-V i_{\max }-V i_{\min }}{V i_{\max }-V i_{\min }}\right]^{20}
$$

Between the two bounds of a variable $V i$ ( $V i_{\max }$ and $V i_{\min }$ ), the maximum of the curve is not a peak but a plateau or large central zone of maximum compatibility or fitness where the function takes the value 1 for a target point $\mathrm{P}$. Then there is a sharp decline outwards to the edges, where it takes the value 0 , and outside this range the values are negative. This effect can be achieved with a value $\delta=2[27,33] . K_{V_{i},}$ assesses the capacity to predict species occurrences that the value $V i_{p}$ of a climatic variable $V_{i}$ acquires at a site $P$ and can be estimated as the inverse of the number of species considered in the model with which $V i_{p}$ is compatible.

$\varphi_{P}^{V_{i}}$ assumes that the degree of suitability for a woodland type will be greater in occurrence sites situated far from the bounds of their 66 convex climatic ranges $\left(0 \leq \phi_{P}^{V i} \leq 1\right)$, and the average of its $m$ values in the $m$ climatic planes can be used as a Phytoclimatic Suitability Index (PSI). Unlike statistical models, the concept of suitability in CLIMPAIR is not related to the frequency of species occurrence within their geographical ranges, and therefore the phytoclimatic position function cannot represent truncated, skewed or bimodal species response in the climatic space.

Thus, using CLIMPAIR we can generate a diagnostic spectrum of the following type in abbreviated annotation $\left(\mathrm{PSI}_{\mathrm{Psy}} ; \mathrm{PSI}_{\mathrm{Fsy}}\right)$, where $\mathrm{PSI}_{\mathrm{Psy}}$ and $\mathrm{PSI}_{\mathrm{Fsy}}(>=0$ and $<=1)$ are indices of relative phytoclimatic suitability of $P$. sylvestris $\left(\mathrm{PSI}_{\mathrm{Psy}}\right)$ and $F$. sylvativa ( $\left.\mathrm{PSI}_{\mathrm{Fsy}}\right)$ forests species with respect to the theoretical optimum $(\mathrm{PSI}=1)$.

The methodology has been put into practice at the Spanish Canfranc weather station, located at an altitude of $1168 \mathrm{~m}$ in the Pyrenees range (lat. $42^{\circ} 44^{\prime} 57^{\prime \prime} \mathrm{N}$, long. $00^{\circ} 31^{\prime} 04^{\prime \prime} \mathrm{W}$ ), over a period stretching from 1910 to 2008 (Figure 1). The dominant forest species is currently $P$. sylvestris with some $F$. sylvatica. The last few decades

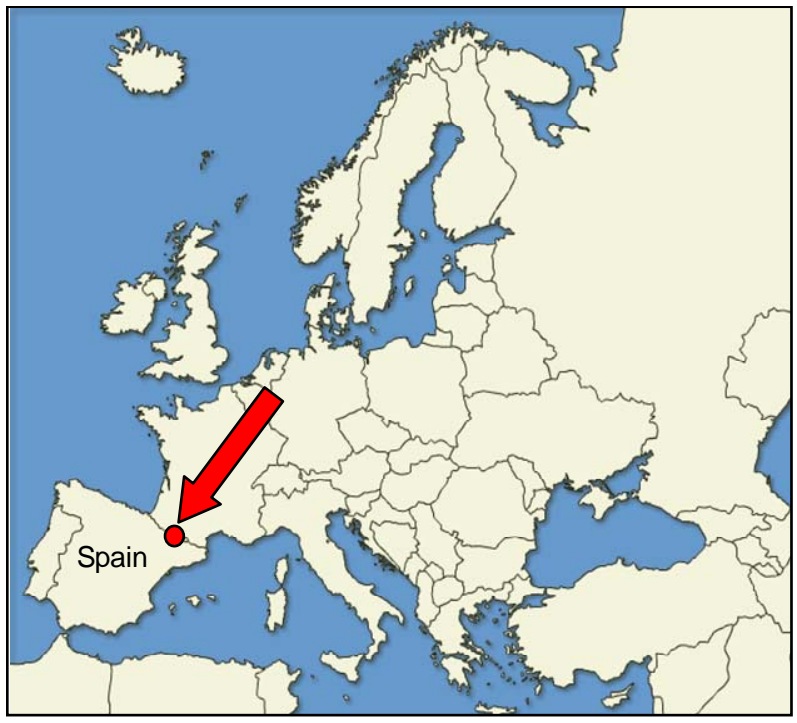

Figure 1. Situation of Canfranc weather station in the Pyrenees range.

have seen an advance of deciduous broadleaf species in areas where conifers have traditionally been predominant.

The phytoclimatic dynamics were assessed with 30year mobile averages of climatic variables in order to filter the natural climatic variability [34] at the Canfranc station over the period from 1910 to 2008 .

The phytoclimatic diagnostic model was applied to the set of climatic values in 30-year mobile averages to generate the diagnostic grid and the variation of PSI. We define $D(t)=$ PSIPsy - PSIFsy as the difference between the suitability indices of $P$. sylvestris and $F$. sylvatica, and $t$ is the time indicator of the series, which takes the value 1 for the first moving average (1910-1939) and 70 for the last one (1979-2008). A comparative statistical evaluation of the trend of the time series of PSI for the two target species was performed by fitting the values of the series to a time function by regression analysis. Several models of evolution with time (linear, logarithmic, quadratic, cubic, logistic, potential and hyperbolic) were assayed.

\section{Results}

Figure 2 shows the evolution of climatic values in 30year mobile averages between 1910 and 2008 for the Canfranc station. We can see that precipitations are relatively stable but there is a clear increase in temperatures based on the mobile averages starting in the 1950s. The mean annual temperature $(\mathrm{T})$ in particular increased by $1.4^{\circ} \mathrm{C}$ between the first (1910-1939) and the last mobile average (1979-2008), and the average of minimum temperatures (TMMF) increased by $2.1^{\circ} \mathrm{C}$ in the same period. 

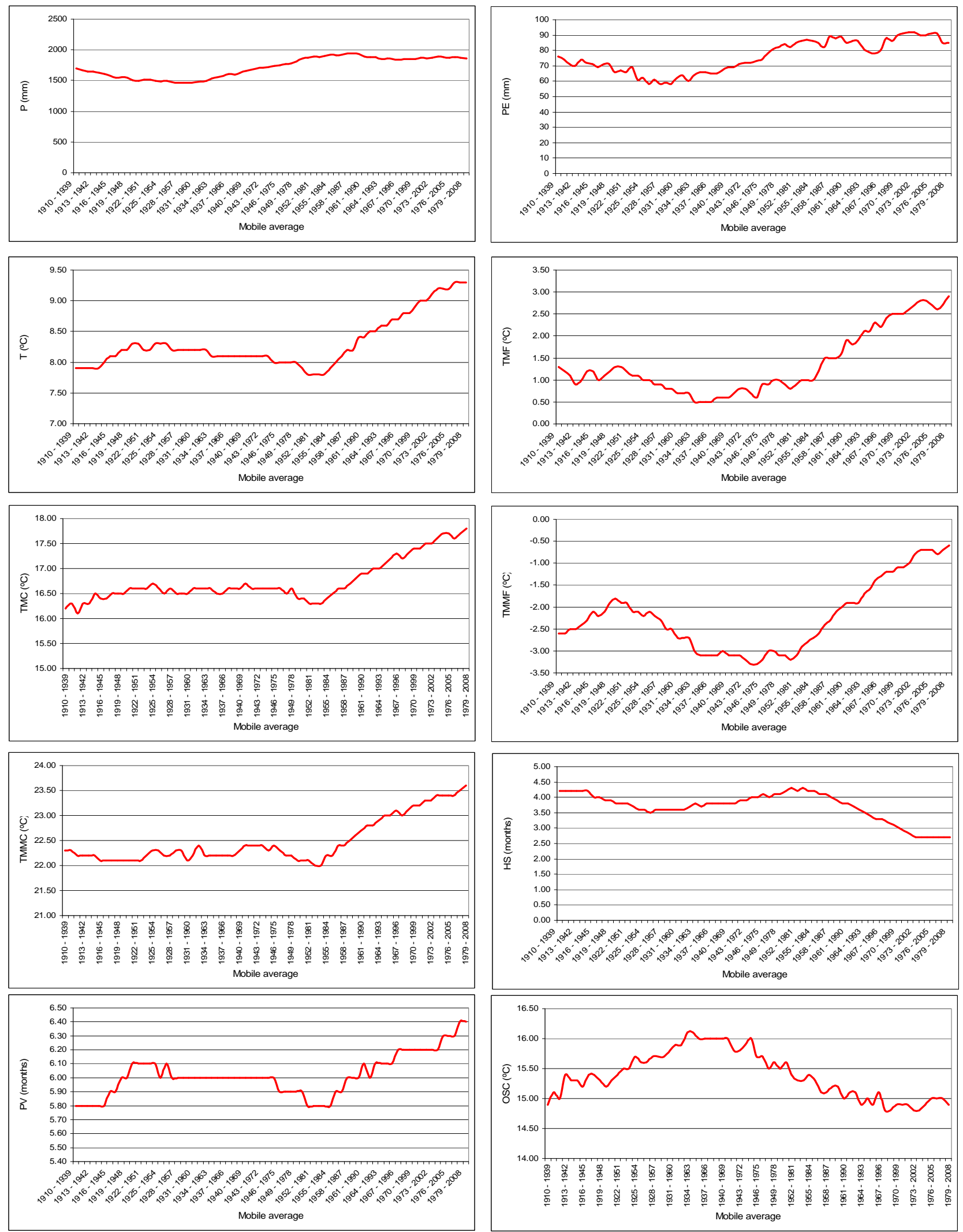

Figure 2. Evolution of climatic values in 30-year mobile averages between 1910 and 2008 for the Canfranc station. $\mathrm{K}$ and $\mathrm{A}$ are not shown because their mobile averages are 0 (See Table 1 for abbreviations). 
Also, the duration of the period with certainty of frosts (HS) declined by 1.5 months and the period of free plant activity (PV) increased by 0.6 month.

The results of applying the phytoclimatic diagnostic model to the set of climatic values in 30-year mobile averages and the variation of the suitability for Pinus sylvestris and Fagus sylvatica are shown in Figure 3.

Starting from roughly the 1934-1963 average the climatic conditions at the station became less suitable for pine growth, and therefore there is a gradual decline in the suitability for pine, while the PSI for the beeches tends to remain stable or decline slightly.

The comparative statistical evaluation of the trend of the time series of PSI for the two target species was per- formed by fitting the values of the series to a time function by regression analysis. Several models of evolution with time (linear, logarithmic, quadratic, cubic, logistic, potential and hyperbolic) were assayed and the best regression function for $D(t)$ in terms of fit $\left(R^{2}=0.97\right.$; standard error $=0.156)$ and overall and individual significance of the parameters (F-statistic and T-statistic) was the cubic model:

$$
D(t)=0.1403+(0.002) \cdot t-\left(3.10^{-5}\right) \cdot t^{2}-\left(6.10^{-7}\right) \cdot t^{3}
$$

Figure 4 shows the observed and predicted values of $D(t)$. The model predicts a situation of stability or equilibrium $(D(t)=0.16)$ up to the period 1934-1963, after which the trend of $D(t)$ is downward and accelerating

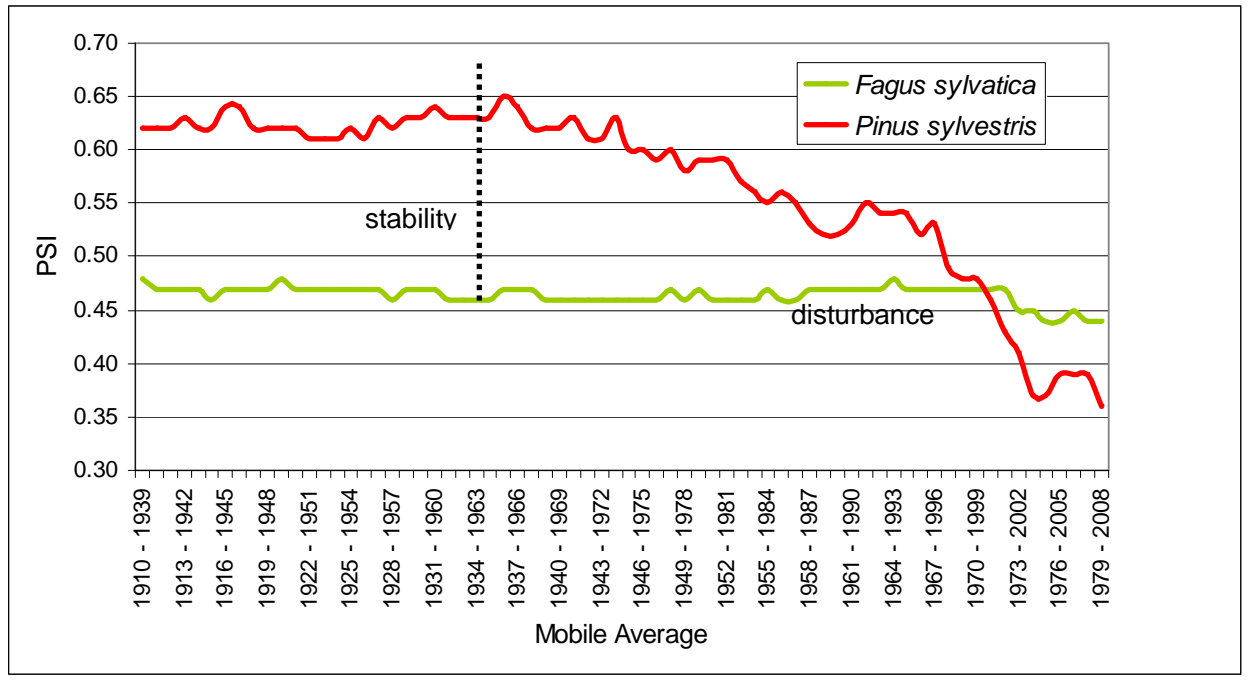

Figure 3. Comparative evolution of the Phytoclimatic Suitability Index (observed values) of Pinus sylvestris and Fagus sylvatica.

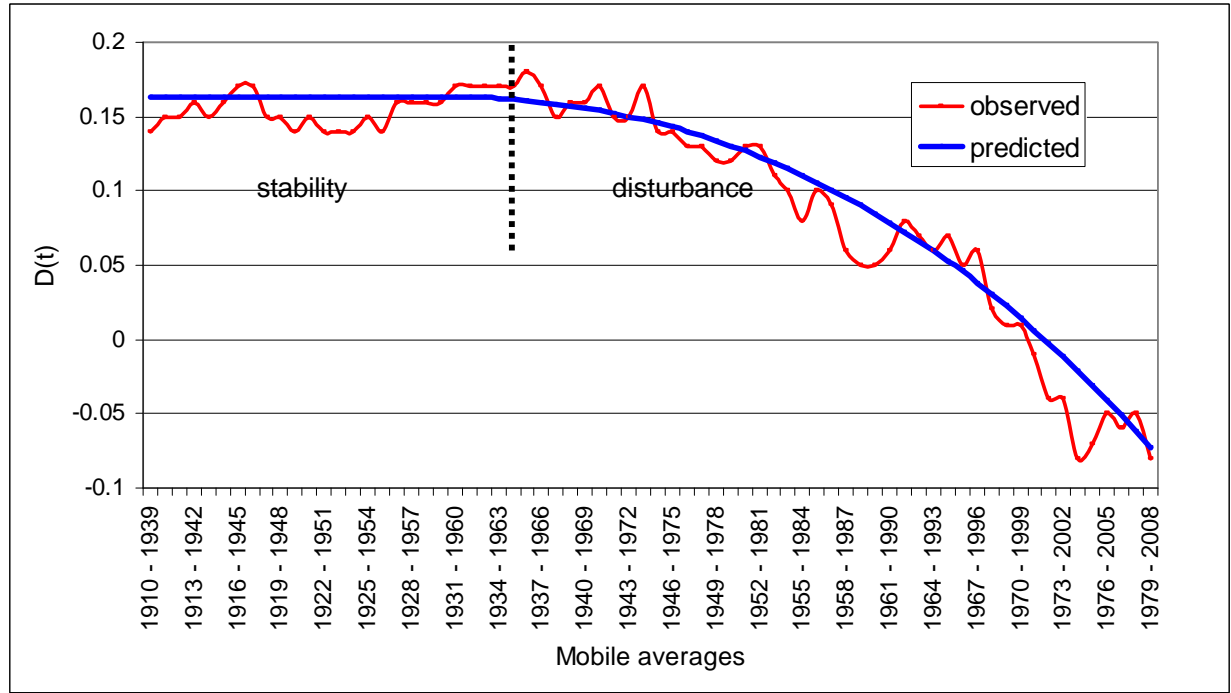

Figure 4. Comparative evolution of the difference in Phytoclimatic Suitability Index of Pinus sylvestris and Fagus sylvatica $D(t)$; observed and predicted values. 
owing to a fall in the PSI of $P$. sylvestris. From 19701999 onwards the model predicts an inversion of the situation as it was up until now, so that beech comes to have a higher PSI than pine.

\section{Discussion}

As our results suggest, the apparent stability between the two target species in Canfranc forest began to break down around the 1934-1963 period, the pine gradually losing ability to compete with the beech in terms of phytoclimatic suitability.

This scenario of decline is chiefly due to the fact that the pine's adjustment to the target site changed more than the beech's. The results indicate that whereas $F$. sylvatica presents relatively stable suitability indices and hence also ability to compete throughout the period considered, the suitability of the climate for pine is in constant decline roughly commencing with the 1934-1963 mobile average. This difference in the suitability for the two species produces a breakdown of the competitive balance in the forest formation, which is actually inverted starting with the 1970-1999 average, since when the conditions for beech were more suitable than for pine.

This development is consistent with morphological characteristics of the two species. The needle-leaf strategies characteristic of $P$. sylvestris are the outcome of adaptation to severe winter cold, long periods of certain frost and short periods of plant activity [35].

Biotic interactions will modulate species' responses to climate change. Many approaches to predicting the impacts of climate change on biodiversity have been based purely on a climate envelope approach and have not considered direct and indirect species interactions [36-38]. From a phytoclimatic standpoint the potential of an area of land to host different types of arboreal forest cover can be studied holistically using mathematical models to determine what principal species of a forest formation are compatible with that area, and also the degree of adjustment of each of these formations to the phytoclimatic environment at the station concerned [39].

This integrated phytoclimatic approach not only provides a means of determining the potential wealth of an area in terms of arboreal forest formations, assessed on the basis of the number of compatible principal species; in addition, by calculating numeric adjustment indicators it is possible to assess the capacity of the medium to host each forest formation, and from there to enter the complex universe of competitive relationships between species and between forest formations by comparing their relative degrees of adjustment. Plant species are limited not only by their absolute limits of survival but also through competition from other species, which might grow better in a given climate $[25,40,41]$. The importance of the competition factor in the distribution of plant species is such that according to some authors [35], the natural limits of distribution of a species will occur where its ability to compete is so depleted by variable environmental conditions that it is supplanted by other species; generally speaking, ecological variables are only decisive at the absolute limits of distribution.

In addition to these limitations we should cite some reservations [9] regarding the construction of the niche since all the possible situations for each species are not taken into account when constructing climatic spaces, particularly due to human influences on the distribution of forest environments in the Mediterranean basin.

An exhaustive comparison with the wide range of predictive models that have been developed in recent years and could be used for this study was beyond the scope of this paper, (e.g. see $[28,29]$ for a review). CLIMPAIR was used because it is correlative and non-statistical and offers an improved definition of the climatic niche as a convex hull instead of a parallelepiped. The suitability concept in statistical models is related to the frequency of species occurrence within their geographical ranges, and then also related both to the frequency of favourable environmental conditions that occur across geographical space, and to historical land use [42].

Phytoclimatic shifts may create new environments comprised of climatic combinations of conditions that did not previously occur and this problem is potentially common in projections of species distribution models $[43,44]$. Forecasting future distributions or suitabilities of species from current species-climate relationships is problematic because the observed distribution of a species alone provides no information about how the species might respond under novel environments [45]. This paper opens up new methodological horizons for the study of climate change effects on the composition and adaptation of forest ecosystems to that change. Such a study needs to be accompanied by improvements in techniques for generating future climatic scenarios so that this methodology can be used to make medium- and long-term estimations.

With this methodology it will be possible to interpret estimations of future changes in temperature and precipitation more efficiently and translate them into plant language, in the form of quantifications of the hosting capacities of environment and the competitive relationships between the principal species in the formation. All this will make it possible to perfect the mechanisms used to make assessments and take preventive and adaptative decisions in future scenarios of phytoclimatic uncertainty. As forest managers prepare for climate change, this 
methodology can provide guidance in developing local and landscape strategies for managing complex forests.

\section{REFERENCES}

[1] M. E. Davis, R. G. Shaw and J. R. Etterson, "Evolutionary Responses to Climate Change," Ecology, Vol. 86, 2005, pp. 1704-1714. doi:10.1890/03-0788

[2] A. Kremer, "How Well Can Existing Forests Withstand Climate Change?” In: J. Koskela, A. Buck and E. Tessier du Cros, Eds., Climate Change and Forest Genetic Diversity: Implications for Sustainable Forest Management in Europe, Bioversity International, Rome, 2007, pp. 3-17.

[3] M. Lindner, M. Maroschek, S. Netherer, A. Kremer, A. Barbati, J. García, R. Seidl, S. Delzon, P. Corona, M. Kolström, M. J. Lexer and M. Marchetti, "Climate Change Impacts, Adaptative Capacity and Vulnerability of European Forest Ecosystems," Forest Ecology and Management, Vol. 259, No. 4, 2010, pp. 698-709. doi:10.1016/j.foreco.2009.09.023

[4] D. L. Spittlehouse and R. B. Stewart, "Adaptation to Climate Change in Forest Management," British Columbia Journal of Ecosystems and Management, Vol. 4, No. 1, 2003, pp. 1-11.

[5] A. E. Ogden and J. L. Innes, "Incorporating Climate Change Adaptation Considerations into Forest Management and Planning in the Boreal Forest," International Forestry Review, Vol. 9, No. 3, 2007, pp. 713-733. doi:10.1505/ifor.9.3.713

[6] R. D. Holt, "The Microevolutionary Consequences of Climate Change," Trends in Ecology and Evolution, Vol. 5, No. 9, 1990, pp. 311-315. doi:10.1016/0169-5347(90)90088-U

[7] J. A. Wiens, D. Stralberg, D. Jongsomjit, C. A. Howell and M. A. Snyder, "Niches, Models, and Climate Change: Assessing the Assumptions and Uncertainties," PNAS, Vol. 106, No. 2, 2009, pp. 19729-19736. doi:10.1073/pnas.0901639106

[8] A. J. Davis, L. S. Jenkinson, J. L. Lawton, B. Shorrocks and S. Wood, "Making Mistakes When Predicting Shifts in Species Range in Response to Global Warming," $\mathrm{Na}$ ture, Vol. 391, 1998, pp. 783-786. doi: $10.1038 / 35842$

[9] R. G. Pearson and T. P. Dawson, "Predicting the Impacts of Climate Change on the Distribution of Species: Are Bioclimate Envelope Models Useful?" Global Ecology and Biogeography, Vol. 12, No. 5, 2003, pp. 361-371. doi:10.1046/j.1466-822X.2003.00042.X

[10] M. B. Araújo and C. Rahbek, "How Does Climate Change Affect Biodiversity?" Science, Vol. 313, No. 5792, 2006, pp. 1346. doi:10.1126/science. 1131758

[11] P. Barnard and W. Thuiller, "Global Change and Biodiversity: Future Challenges," Biology Letters, Vol. 4, No. 5, 2008, pp. 553-555. doi:10.1098/rsbl.2008.0374

[12] W. Thuiller, S. Lavorel, M. T. Sykes and M. B. Araújo, "Using Niche-Based Modelling to Assess the Impact of Climate Change on Tree Functional Diversity in Europe,"
Diversity and Distributions, Vol. 12, No. 1, 2006, pp. 4960. doi:10.1111/j.1366-9516.2006.00216.x

[13] M. Benito, R. Sánchez de Dios and H. Sainz-Ollero, "Effects of Climate Change on the Distribution of Iberian Tree Species," Applied Vegetation Science, Vol. 11, No. 2, 2008, pp. 169-178. doi:10.3170/2008-7-18348

[14] F. M. Chmielewski and T. Rötzer, "Response of Tree Phenology to Climate Change across Europe," Agricultural and Forest Meteorology, Vol. 108, No. 2, 2001, pp. 101-112. doi:10.1016/S0168-1923(01)00233-7

[15] P. A. Harrison, P. M. Berry, N. Butt and M. New, "Modelling Climate Change Impacts on Species' Distributions at the European Scale: Implications for Conservation Policy," Environmental Science \& Policy, Vol. 9, No. 2, 2006, pp. 116-128. doi:10.1016/j.envsci.2005.11.003

[16] D. Tonti, C. Estreguil, M. Marchetti, K. Oehmichen, G. Chirici, K. Troeltzsch and K. Watts, "Linking and Harmonizing Forest Spatial Pattern Analyses at European, National and Regional Scales for a Better Characterization of Forest Vulnerability and Resilience," European Commission, Joint Research Centre and Institute for Environment and Sustainability, 2010.

[17] J. M. García-López and C. Allué, "A PhytoclimaticBased Indicator for Assessing the Inherent Responsitivity of the European Forests to Climate Change," Ecological Indicators, Vol. 18, 2010, pp. 73-81. doi:10.1016/j.ecolind.2011.10.004

[18] R. M. M. Crawford, "Plants at the Margin. Ecological Limits and Climate Change," Cambridge University Press, Cambridge, 2008. doi:10.1017/CBO9780511754906

[19] F. K. Holtmeier, "Mountain Timberlines. Ecology, Patchiness, and Dynamics. Advances in Global Change Research," Kluwer Academic Publishers, Dordrecht, Boston, London, 2003.

[20] M. Barbéro, R. Loisel and P. Quézel, "Pines of the Mediterranean Basin," In: D. M. Richardson, Ed., Ecology and Biogeography of Pinus, Cambridge University Press, Cambridge, 1998, pp. 153-170.

[21] I. Cañellas, F. Fartínez and G. Montero, "Silviculture and Dynamics of Pinus sylvestris L. Stands in Spain," Investigación Agraria. Sistemas y Recursos Forestales, Vol. 1, No. 1, 2000, pp. 233-253.

[22] U. Cubash, H. Von Storch, J. Wastewitz and E. Zorita, "Estimates of Climate Change in Southern Europe Derived from Dynamical Climate Model Output," Climate Research, Vol. 7, No. 2, 1996, pp. 129-149. doi: $10.3354 / \mathrm{cr} 007129$

[23] R. T. Watson, M. C. Zinyowera and R. H. Moss, ”The Regional Impacts of Climate Change: An Assessment of Vulnerability," Special report of IPCC Working Group II, Cambridge University Press, Cambridge, 1997.

[24] E. Gutiérrez, "Dendroecological Study of Fagus sylvatica L. in the Montseny Mountains (Spain)," Acta Oecologica Oecology Plant, Vol. 9, 1988, pp. 301-309.

[25] A. Baselga and M. B. Araújo, 'Individualistic vs. Community Modelling of Species Distributions under Climate change," Ecography, Vol. 32, No. 1, 2009, pp. 55-65. 
doi:10.1111/j.1600-0587.2009.05856.x

[26] M. B. Araújo amd M. Luoto, "The Importance of Biotic Interactions for Modelling Species Distributions under Climate Change," Global Ecology and Biogeography, Vol. 16, No. 6, 2007, pp. 743-753. doi:10.1111/j.1466-8238.2007.00359.x

[27] J. M. García-López and C. Allué, "Modelling Phytoclimatic Versatility as a Large Scale Indicator of Adaptive Capacity to Climate Change in Forest Ecosystems," Ecological Modelling, Vol. 222, No. 8, 2011, pp. 1436-1447. doi:10.1016/j.ecolmodel.2011.02.001

[28] R. G. Pearson, "Species' Distribution Modelling for Conservation Educators and Practitioners," Lessons in Conservation, Vol. 3, 2010, pp. 54-89.

[29] J. Franklin, "Mapping Species Distributions. Spatial Inference and Prediction," Cambridge University Press, Cambridge, 2009.

[30] G. E. Hutchinson, "Concluding Remarks," Cold Spring Harbor Symposium on Quantitative Biology, Vol. 22, 1957, pp. 415-457. doi:10.1101/SQB.1957.022.01.039

[31] F. P. Preparata and M. I. Shamos, "Computational Geometry: An Introduction," Springer-Verlag, New York, 1985.

[32] W. K. Cornwell, D. W. Schwilk and D. D. Ackerly, "A Trait-Based Test for Habitat Filtering: Convex Hull Volume," Ecology, Vol. 87, No. 10, 2006, pp. 1070-1080.

[33] J. L. Allué-Andrade, "Atlas fitoclimáTico de España. Taxonomías. Phytoclimatic Atlas of Spain. Taxonomies," Ministerio de Agricultura, Pesca y Alimentación. Instituto Nacional de Investigaciones Agrarias, Madrid, 1990.

[34] M. Brunet, M. J. Casado, M. De Castro, P. Galán, J. A. López, J. M. Martín, A. Pastor, E. Petisco, P. Ramos, J. Ribalaygua, E. Rodríguez, I. Sanz and L. Torres, "Generación de Escenarios Regionalizados de Cambio Climá Tico Para España," Agencia Estatal de Meteorología, Madrid, 2008.

[35] H. Walter, "Vegetationszonen und Klima," Eugen Ulmer, Stuttgart, 1970

[36] P. E. Hulme, "Adapting to Climate Change: Is There Scope for Ecological Management in the Face of a Global Threat?" Journal of Applied Ecology, Vol. 42, No. 5, 2005, pp. 784-794. doi:10.1111/j.1365-2664.2005.01082.x

[37] E. S. Poloczanzka, S. J. Hawkins, A. J. Southward and M. T. Burrows, "Modelling the Response of Populations of
Competing Species to Climate Change," Ecology, Vol. 89, No. 11, 2008, pp. 3138-3149. doi:10.1890/07-1169.1

[38] T. D. Price and M. Kirkpatrick, "Evolutionarily Stable Range Limits Set by Interspecific Competition," Proceedings B of the Royal Society, Vol. 276, No. 1661, 2008, pp. 1429-1434. doi:10.1098/rspb.2008.1199

[39] A. Guisan and W. Thuiller, "Predicting Species Distribution: Offering More than Simple Habitat Models," Ecology Letters, Vol. 8, No. 9, 2005, pp. 993-1009. doi:10.1111/j.1461-0248.2005.00792.x

[40] X. Morin and I. Chuine, "Niche Breadth, Competitive Strength and Range Size of Tree Species: A Trade-Off Based Framework to Understand Species Distribution," Ecology Letters, Vol. 9, No. 2, 2006, pp. 185-195. doi:10.1111/j.1461-0248.2005.00864.X

[41] W. Thuiller, C. Albert, M. B. Araújo, P. M. Berry, M. Cabeza, A. Guisan, T. Hickler, G. F. Midgley, J. Paterson, F. M. Schurrh, M. T. Sykes and N. E. Zimmermann, "Predicting Global Change Impacts on Plant Species' Distributions: Future Challenges," Perspectives in Plant Ecology, Evolution and Systematics, Vol. 9, No. 3-4, 2008, pp. 137-152. doi:10.1016/j.ppees.2007.09.004

[42] O. Broennimann, W. Thuiller, G. O. Hughes, G. F. Midgley, J. R. M. Alkemade and A. Guisan, "Do Geographic Distribution, Niche Property and Life Form Explain Plants Vulnerability to Global Change?" Global Change Biology, Vol. 12, No. 6, 2006, pp. 1079-1093. doi:10.1111/j.1365-2486.2006.01157.x

[43] J. W. Williams, S. T. Jackson and J. E. Kutzbach, "Projected Distributions of Novel and Disappearing Climates by 2100 AD," PNAS, Vol. 104, No. 14, 2007, pp. 57385742. doi:10.1073/pnas.0606292104

[44] J. M. García-López and C. Allué, "Modelling Future No-Analogue Climate Distributions: A World-Wide Phytoclimatic Niche-Based Survey," Global and Planetary Change, Vol. 101, 2013, pp. 1-11. doi:10.1016/j.gloplacha.2012.12.001

[45] M. C. Fitzpatrick and W. W. Hargrove, "The Projection of Species Distribution Models and the Problem of Non-Analog Climate," Biodiversity and Conservation, Vol. 18, No. 8, 2009, pp. 2255-2261. doi:10.1007/s10531-009-9584-8 